PAPER

\title{
Changes in artistic style after minor posterior stroke
}

\author{
J M Annoni, G Devuyst, A Carota, L Bruggimann, J Bogousslavsky
}

See end of article for

J Neurol Neurosurg Psychiatry 2005;76:797-803. doi: 10.1136/jnnp.2004.045492

authors' affiliations

....................

Correspondence to: Julien Bogousslavsky, Department of Neurology, Lausanne University Hospital, CH 1011

Lausanne, Switzerland; Julien.Bogousslavsky@ chuv.hosprd.ch

Received 12 May 2004 Revised version received 13 September 2004 Accepted

13 September 2004

\begin{abstract}
Background: Two professional painters experienced significant changes in their art as the main consequence of minor stroke located in the left occipital lobe or thalamus.

Methods: The features of this artistic conversion were analysed on the basis of extensive neurological, neuropsychological, and psychiatric evaluations.

Results: Both painters, initially unaware of the artistic changes, exhibited mild signs of executive dysfunction, but no general cognitive decline. The first painter, who showed mild visual-perceptive difficulties (dyschromatopsia and scotoma in his right upper visual field after left occipital stroke), together with increased anxiety and difficulty in emotional control, switched to a more stylised and symbolic art. The second painter, who also presented features of emotionalism related to his left latero-thalamic stroke, switched from an impressionist style to a more joyous and geometric, but more simplistic, abstract art. Conclusions: These findings show that mild cognitive and affective modifications due to focal posterior brain lesions can have significant repercussions on artistic expression.
\end{abstract}

$\mathrm{P}$ ainting is a very complex behaviour ${ }^{1}$ and its neural correlates involve brain areas processing the perceptive, cognitive, and emotional valences of stimuli; brain damage, therefore, could modify artistic expression. The effect of a major stroke on artistic changes as a function of the lesion type has been the subject of several reports, which have generally focused on the result of severe visuo-spatial disturbances (that is, hemispatial neglect) ${ }^{2}{ }^{3}$ and aphasic disintegration. ${ }^{3}{ }^{4}$ Right parieto-occipital damage resulting in spatial neglect, constructional apraxia, or perceptual agnosia can alter the spatial configuration of the whole painting or individual parts, ${ }^{5-8}$ while extensive left hemisphere damage may be responsible for simplification of detail of represented objects. ${ }^{3}$

Another aspect to consider is that, in a limited number of cases, brain disorders seem, paradoxically, to improve artistic expression. Painters with fronto-temporal dementia and predominant left hemisphere dysfunction generally lose their capacities of abstraction and symbolic representation, but their paintings may appear more emotional and creative. ${ }^{9-11}$ Alzheimer's disease and Lewy body dementia, in which visuo-spatial disturbances may be prominent, adversely affect drawing ability, but, in certain cases, painting become more intuitive and fluid. ${ }^{12-14}$ From published reports of painters with dementia, we can draw some conclusions about the relationships between brain disorders and painting. In some cases, a surprising outburst of creativity corresponds with the loss of inhibitory control, leading to a sort of artistic disinhibition. ${ }^{15} 16$ For example, in patients with semantic dementia and predominant left hemisphere atrophy, facilitation of creativity has been attributed to a mechanism called "paradoxical functional facilitation", ${ }^{17}$ corresponding to a shift from a left to a right hemisphere mode of functioning.

The effect of lesions within fronto-subcortical networks subserving executive functions might be more subtle. Executive functions may intervene in painting in the process of screening the figurative relevance of stimuli or in expressing novel order relationships between concepts. ${ }^{18}$ Furthermore, lesions limited to the limbic and paralimbic regions involved in the regulation of mood and emotional states should also affect an artist's work. Creativity in painters has always been related to the emotional features

of the artist's unique personality, and periods of intense artistic activity have frequently been compared to hypomanic states. ${ }^{16}{ }^{19}$ Depression, anxiety, emotional dyscontrol, apathy, indifference, mania, and psychosis, all of which are known possible affective consequences of focal infarcts, ${ }^{20-22}$ can have a major influence on art, even after only limited brain damage. The possibility that focal and limited brain lesions might specifically influence an artist's style through executive or affective changes has been poorly investigated. Here, we present two painters, both of whom had a limited stroke in the area of the left posterior cerebral artery and recovered from their sensory motor deficits, but whose artistic expression was modified.

\section{CASE REPORTS}

\section{Patient 1}

Patient 1 was a 57 year old right handed lithographer and described himself as a self taught painter. The themes of his paintings were principally simplified human representations (fig 1A), semi-figurative scenes, and original geometric shapes. His pictorial language was rather naive, influenced by primitive expressive styles (explanations of artistic terms can be found in appendix A).

He presented a sudden loss of vision in the superior right visual field and an autoscopic phenomenon (he saw himself lying on the floor with his head turned to the left). He also noticed difficulty in perceiving complex objects in his upper right visual field. The first neurological examination showed a right superior quadrantopia sparing macular vision, confirmed by a detailed ophthalmologic evaluation. An MRI revealed an acute ischemic infarct in the occipital area corresponding to parts of V1 and V2 (fig 2). Arterial dissection was excluded by MR angiographic and Doppler findings, ECG monitoring did not reveal intermittent atrial fibrillation, and other causes, such as diabetes, vasculitis, or procoagulant states, were ruled out. The presumptive cause was a paradoxical embolism from a patent foramen ovale and he was treated with oral anticoagulants. Within a few days, the right superior quadrantopia reduced to a paracentral

Abbreviations: DEX, Dysexecutive Questionnaire; MMSE, Mini Mental State Evaluation; PTSD, post-traumatic stress disorder 

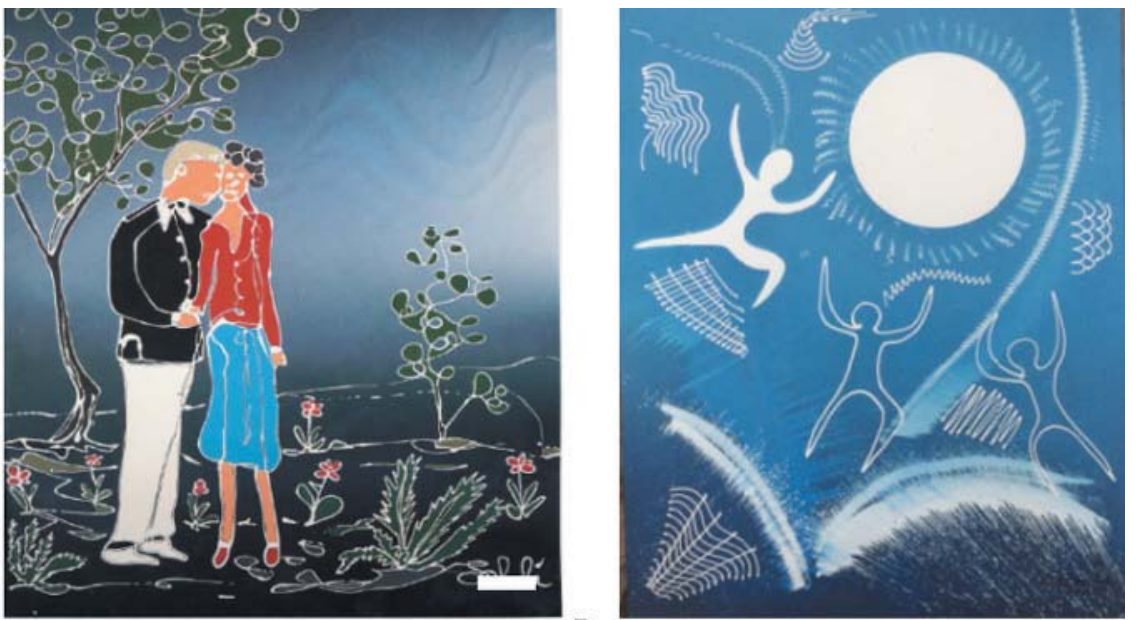

Figure 1 Paintings by patient 1 some months before $(A)$ and 4 months after (B) stroke. The scenes were chosen because of their similarity to highlight the small stylistic changes.

A

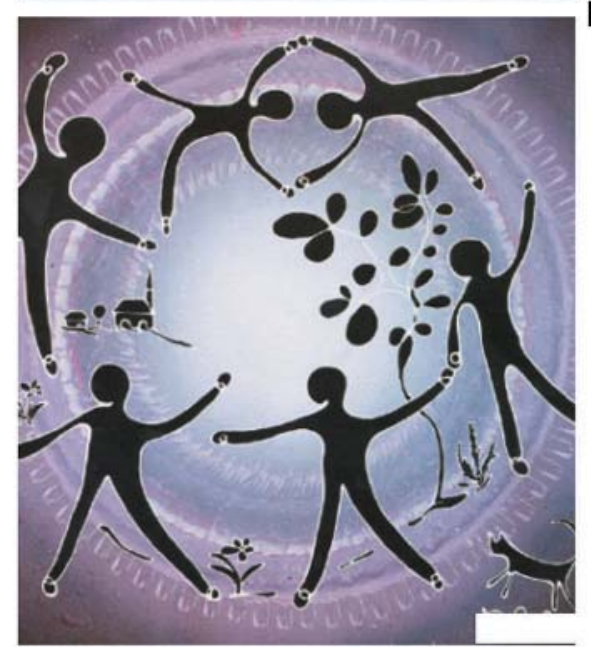

,

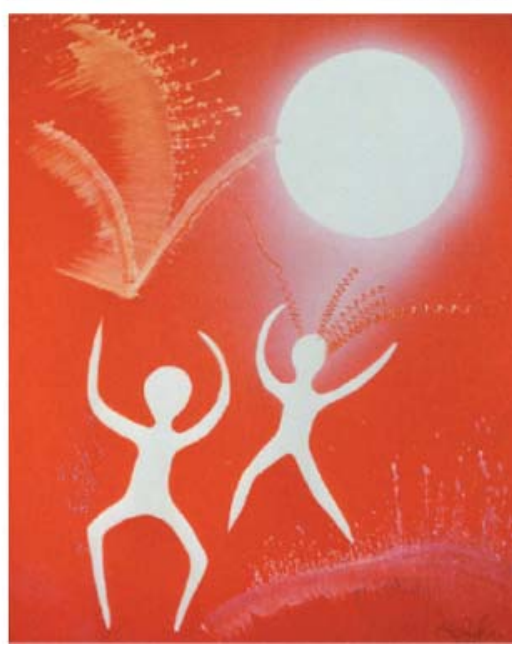

scotoma, but a dazzling flash or white lines and contours (mimicking the "shapes of fish skin and burning paper") would frequently appear in the upper right visual quadrant. Neurological examination 2 months after stroke showed a right superior paracentral scotoma at $30^{\circ}$ degrees and a dyschromatopsia in the spared right upper visual field. Repeated EEGs did not reveal any epileptic discharges. At the 5 month follow up, neuropsychological assessment (table 1) showed minor changes, such as a tendency to digress in his discourse, a slightly delayed response times in both visual fields in a visual detection task, and a tendency to perseveration in a figural fluency task, but a normal performance in go-nogo and Stroop-like tasks. There was no general cognitive decline in the Mini Mental State Evaluation (MMSE $=29 / 30)$. Oral and written language, constructional, ideational, and ideomotor praxis, and episodic and short term memory were normal. He denied any difficulty in recognising familiar shapes when looking for someone in the street, when reading magazines, or when looking at paintings. According to his wife, he had no problems conducting his professional life and was independent in terms of travelling alone, organising his exhibitions, and taking care of his bills. We diagnosed a mild dysexecutive syndrome. A psychiatric interview showed no personality changes after stroke, but did show increased impulsiveness, fluctuating depressive mood, and increased anxiety and avoidance behaviour, suggestive of a moderate post-traumatic stress disorder (PTSD). This PTSD-like syndrome was confirmed by a pathological scoreparticularly for the avoidance symptoms-in the Impact of Event Scale. ${ }^{23}$ Moreover, some irrational ideas were found, but these related only to the cause of the stroke (for example, family problems), and the diagnosis of a psychotic reaction was excluded. The Dysexecutive Questionnaire (DEX) 24 showed a relatively higher score in the items of emotional dyscontrol and loss of motivation compared to other items. Patient 1 did not report any change in his habits, taste, eating, or aesthetic judgment.

He started drawing and painting 1 month after the stroke and, after a few weeks, comments by relatives and clients made him aware that some changes had occurred in his art. Human limbs and hands were thinner, sharper, and more stylised (fig 1B) and the details simplified. Compared to his

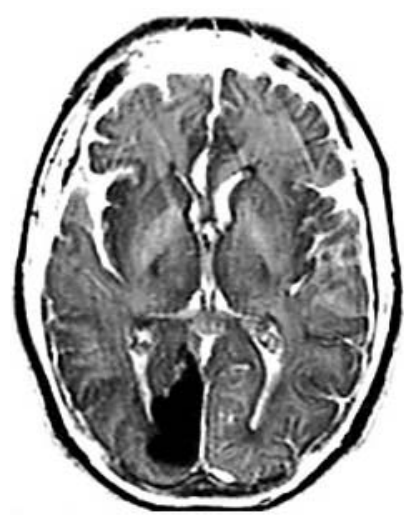

Figure 2 Patient 1's occipital stroke, as shown in an MRI 3 weeks after the acute event. Fast spin echo T2 (TR: $3800 \mathrm{~ms}$, TE: $90 \mathrm{~ms}$, NEX: 2, FOV: $173 \times 230$ matrix: $190 \times 256,30 \%$ gap) $5 \mathrm{~mm}$ thick transverse section. 
Table 1 Summary of neuropsychological data for patients 1 and 2

\begin{tabular}{|c|c|c|}
\hline \multirow[b]{2}{*}{ Domains } & \multicolumn{2}{|l|}{ Scores } \\
\hline & Patient 1 & Patient 2 \\
\hline \multicolumn{3}{|l|}{ Gnosia } \\
\hline Recognition of embedded figures (POP) & $9 / 9$ & $8 / 8$ \\
\hline $\begin{array}{l}\text { Hooper visual organisation test } \\
\text { (adapted version) }\end{array}$ & $15 / 20$ & $14 / 20$ \\
\hline $\begin{array}{l}\text { Recognition of celebrities (actors, } \\
\text { politicians, etc) }\end{array}$ & $5 / 5$ & $5 / 5$ \\
\hline Recognition of facial emotions & $12 / 12$ & $12 / 12$ \\
\hline Colour naming & $10 / 10$ & $10 / 10$ \\
\hline Position discrimination (BORB) & $33 / 40$ & NA \\
\hline $\begin{array}{l}\text { Object recognition in non-canonical } \\
\text { views (BORB) }\end{array}$ & $25 / 25$ & $6 / 6$ \\
\hline Stereognosia (objects, right hand) & $5 / 5$ & $6 / 7$ \\
\hline Stereognosia (objects, left hand) & $5 / 5$ & $5 / 7$ \\
\hline \multicolumn{3}{|l|}{ Semantic memory } \\
\hline Semantic memory: Columbia & $11 / 12$ & $9 / 12$ \\
\hline $\begin{array}{l}\text { Semantic memory: description of } \\
\text { visual features }\end{array}$ & $6 / 6$ & $8 / 12^{*}$ \\
\hline \multicolumn{3}{|l|}{ Executive functions } \\
\hline Phonological fluency (1 min) & 16 & $5^{*}$ \\
\hline Categorical fluency (1 min) & 17 & 15 \\
\hline Design fluency (repetitions) & $41\left(6^{*}\right)$ & $38\left(6^{*}\right)$ \\
\hline $\begin{array}{l}\text { Perseveration in Luria's graphomotor } \\
\text { tasks }\end{array}$ & $3 / 20^{*}$ & $2 / 20^{*}$ \\
\hline Clinical go/nogo task & $10 / 10(N)$ & $10 / 10(N)$ \\
\hline $\begin{array}{l}\text { Non-colour Stroop (interference/ } \\
\text { naming phase) }\end{array}$ & $<2(\mathrm{~N})$ & $<2(\mathrm{~N})$ \\
\hline \multicolumn{3}{|l|}{ Behaviour/emotional scales } \\
\hline Global DEX score & $5 / 80^{*}$ & $10 / 80^{*}$ \\
\hline Occasional emotional signs (reported & & \\
\hline in the DEX) & Apathy & Impulsiveness \\
\hline Other artistic/diet changes & None & None \\
\hline \multicolumn{3}{|l|}{ Psychiatric scales } \\
\hline HAD Depression & $4 / 21$ & $7 / 21$ \\
\hline HAD Anxiety & $16 / 21 *$ & $6 / 21$ \\
\hline IES scale & $>30$ & NA \\
\hline
\end{tabular}

*Normal: $<18$

$\mathrm{N}$, normal; NA, not assessed. Impaired performances are indicated by an asterisk. Abbreviations for the tests ${ }^{42}$ : BORB, Birmingham Object

Recognition Battery; Columbia, Columbia Association Test; POP,

Poppelreuter's figures; RAVLT, Rey's Auditory Verbal Learning test. Recognition of facial emotions is part of a prosopagnosia battery. ${ }^{43}$ The adapted Hooper and Stroop-like tests were developed in Lausanne. ${ }^{44}$ Mood alterations were evaluated using the French version of the Hospital Anxiety and Depression Scale (HAD) $)^{45}$ and PTSD-like symptoms were assessed using the Impact of Event Scale (IES). ${ }^{46}$

previous paintings, there was an overall simplification as a result of the increased use of monochromic colour choices, more stylised figures, and unreferenced background spaces. He also introduced the luminous features that appeared in his scotoma (fig 1B, top picture, bottom left corner; bottom picture, top left corner). He showed us six examples from before the stroke and four from after the stroke, which confirmed these changes. Four of these (two from before and two from after the stroke) were shown to two independent judges who concluded there was simplification and increased abstraction, symbolism, and role of luminosity (see appendix B). His method of painting itself was also altered; as he said, "Previously, I would lie down and visualise a canvas for an hour before starting to paint. Now, the flash prevents me from doing this. My inspiration comes a little at a time while painting, rather than before I start".

\section{Patient 2}

Patient 2, a 71 year old ambidextrous retired bank clerk, developed a great interest in painting from the age of 50 and exhibited locally and nationally. His favourite themes were Swiss landscapes and he avoided purely abstract representation. Critics defined his art as "figurative-impressionist". He first came to our attention because of sudden right hypoesthesia-hemiataxia-hemiparesis, from which he recovered completely within $24 \mathrm{~h}$. An MRI showed a small lesion in the area of the thalamo-perforant branches (fig 3). Intermittent atrial fibrillation was noted and treatment with oral anticoagulants started.

A standardised neuropsychological evaluation 1 year after the stroke (table 1) revealed a slight impairment in executive functions, as demonstrated by a moderate tendency to perseveration in verbal (phonological) and figural fluency tasks and by some lack of precision in semantic and mental imagery tasks (for example, in a word definition task, he said, "An elephant, this is the largest animal on earth, with tusks... I am not sure about its colour; does it have hooves?"). The MMSE showed no cognitive decline (28/30). Oral and written language, constructional, ideational, and ideomotor praxis, and episodic and short term memory were normal, as were auditory and somesthetic tasks of interhemispheric transfer. According to his wife, he had no problems carrying out social activities. In a self administered DEX questionnaire, the patient only scored high on two items, impulsiveness and lack of interest in social rules. We diagnosed a mild to moderate dysexecutive syndrome. A psychiatric interview led to the diagnosis of an absence of any clinically relevant personality change, but the appearance of mild emotional dyscontrol. Moreover, the consultant did not suggest any psychiatric disorder. The painter's wife completed a questionnaire on personality changes (the Iowa Scale of Personality Change, ISPC ${ }^{26}$ ), comparing his personality before and after the stroke, which confirmed that the only change was the development of this slight emotional dyscontrol.

He started to paint again 2 weeks after stroke, initially with his left hand, then alternating between the left and right hands, a method he had never used before the stroke. Even though the strength and motility of the right hand had completely recovered, he intended to train his left hand in case his right hand was again paralysed. He sold his new paintings with the same success as before. It was not until several months later that comments by clients and critics made him realise that his art had changed.

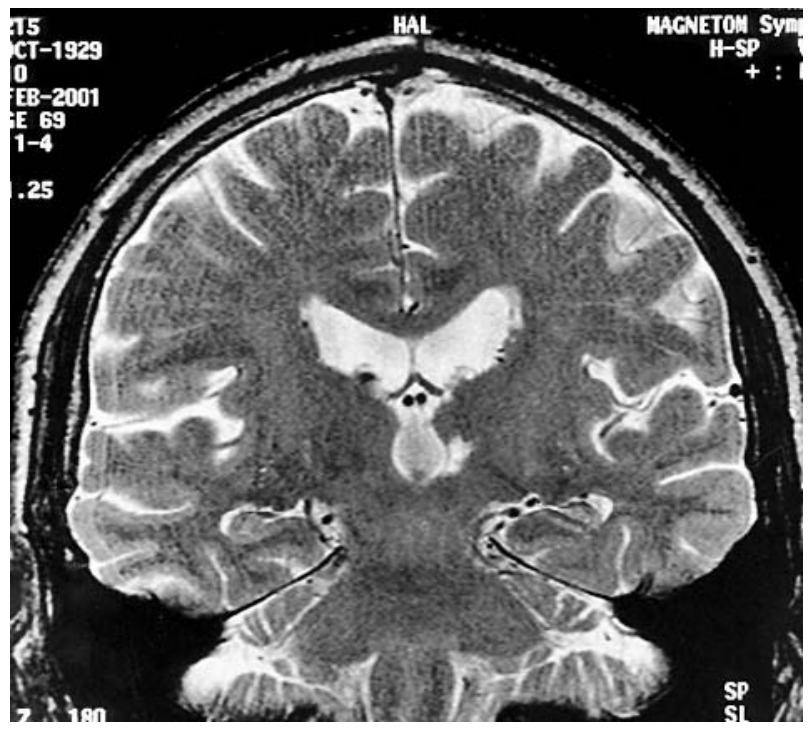

Figure 3 Patient 2's left paramedian thalamic stroke, as shown in an MRI 6 weeks after the acute event. Fast spin echo T2 (TR: 3800 ms, TE: 90 ms, NEX: 2, FOV: $173 \times 230$, matrix: $190 \times 256,30 \%$ gap) $5 \mathrm{~mm}$ thick transverse section. 
Patient 2 switched from a "figurative" to a more "realistic" art, in which colour intensity, a search for more realistic shape consistency, a focus on detail, and a more structured organisation of space were the most important features (fig 4). He showed us three examples from before and three from after the stroke, which confirmed these changes. Two independent judges concluded that, after stroke, there was more geometric organisation and use of bolder colours and a greater relevance of each detail of the painting (see appendix B).

He reported that he was "more sensitive to the hidden beauty of nature" and that he "wanted to live and paint spontaneously, explore the world, and represent it in its raw strength". He also indicated a loss of interest in "impressionists", whom he had preferred for the previous 21 years. Impressionism was now no longer sufficiently real or representative of his creative strength. Intriguingly, he said that it was the use of the left hand that led him into this new artistic dimension. In fact, he discovered that figures executed with his left hand had more emotional strength and bolder colours, whereas, in those painted with the right hand, the lines, contours, and perspectives were clearer. He realised that his creativity was increased by the use of his left hand. Patient 2 showed us three canvases representing the same subject, painted with the left, right, or both hands, respectively, which demonstrated that the painting produced using the left hand employed more vivid colours (fig 5).

Apart from painting, patient 2 did not notice any changes in his previous habits. His relatives and friends did not report any change in his behaviour or personality after stroke. At the 1 year follow up, patient 2 's artistic productivity remained high.

\section{DISCUSSION}

Our two patients were talented painters who experienced qualitative artistic changes as the main consequence of a stroke in the area of the left posterior cerebral artery. Other behavioural consequences included moderate executive dysfunction and features of emotional dyscontrol, but no general cognitive impairment. The possibility that the artistic changes were due to a conscious personal choice following a life threatening medical event was initially considered; however, both patients were initially unaware of the changes to their art, suggesting that the change was due not to personal choice, but was neurological in origin. Reduced insight into a cognitive or behavioural modification is often a direct consequence of brain dysfunction. ${ }^{27}$ Patient 2 evolved initially towards bimanual painting. However, we did not consider that the artistic changes were related to bimanual painting, since the subjective feeling of the painter in parallel was of a more general creative freedom, regardless of the hand used. The fact that, in both painters, the changes only involved painting, and not other habits or activities, also led us to discount an effect on creativity related to general effects, such as novelty seeking. Moreover, modification of novelty seeking is generally related to frontal lesions ${ }^{28}$ while our patients had stroke in the posterior circulation.

The artistic changes may have been associated with a direct effect of the infarct. Since the posterior brain regions seem to play a specific role in creative thinking, ${ }^{29}$ it is not surprising that a minor lesion in these regions might alter an artist's creative thought and thus his style of painting. ${ }^{18}$ Besides, the fact that patients 1 and 2 had left hemispheric dysfunction may provide some support for the theory of "right hemisphere functional release ${ }^{\prime \prime}{ }^{17}$ Different possible cognitive mechanisms may be considered.

Firstly, given that artistic modifications after posterior strokes are often due to alterations in perceptual ${ }^{7}$ or spatial and visuo-constructive ${ }^{30} 31$ activity or mental imagery, ${ }^{8}$ such neuropsychological alterations may be the cause of the artistic changes. However, we found no evidence of spatial deficit or constructional apraxia. ${ }^{31}$ Patient 2 showed mild signs of semantic impairment in verbally describing characteristics of animals or objects, but the fact that, after stroke, his painting was more structured and detailed suggests that mental imagery was well preserved.

Secondly, creativity is also modulated by evaluative judgements ${ }^{32}$ and executive functions. ${ }^{16}$ The role of the thalamus and posterior brain structures in executive functions has been reported ${ }^{33-35}$ and is supported by data from functional imaging studies. ${ }^{36}$ Simplification of drawing and attention to detail have both been described in some patients with frontal dementia. ${ }^{15}$ Therefore, moderate executive dysfunction in both painters could be partly associated with their artistic changes. This hypothesis is strengthened by both patients' modified performances in verbal or visual fluency tasks, which are executive tasks, but have also been used as a short test of divergent thinking and creativity. ${ }^{37}$

However, fact that the artistic changes were different in patients 1 and 2 suggested that executive dysfunction was not the only mechanism. Both painters also showed poststroke emotional changes, which may also be considered..$^{22} 38$ In the case of patient 1 , the main artistic change was the way he drew human figures. He also used a less structured background in his paintings, and the relationship between light and shapes appeared less developed than before. A general simplification of his art developed after his stroke. Increased anxiety and avoidance behaviour could have played a role in this general simplification. ${ }^{39}$ In the case of patient 2 , the main pictorial changes were a conversion to a more

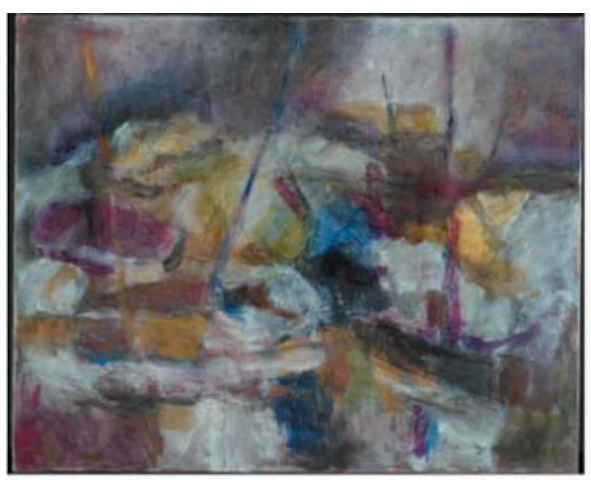

Before stroke

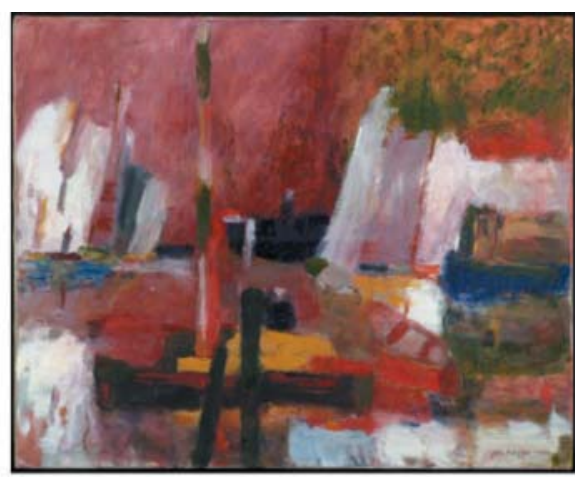

Figure 4 Paintings by patient 2 before and after stroke. Note the use of more vivid colours after stroke. 


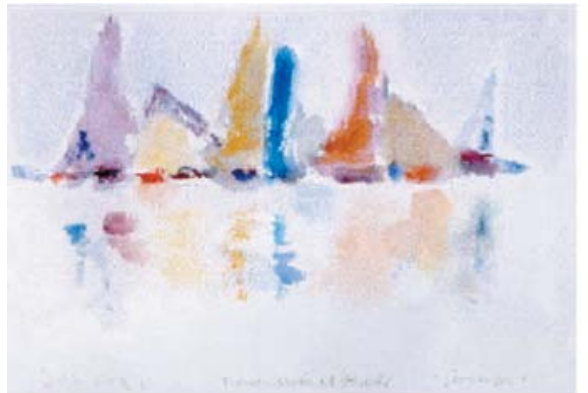

Left hand

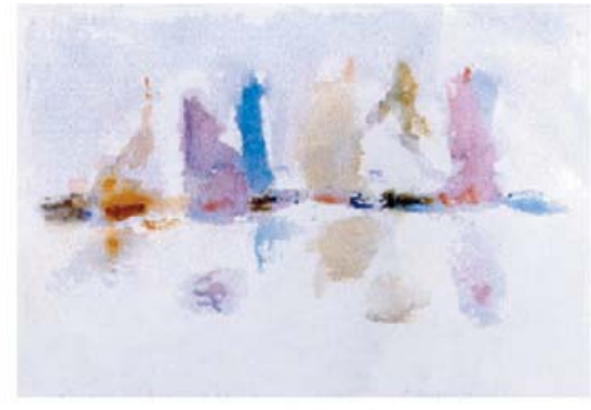

Right hand
Figure 5 Pictures painted by patient 2 some weeks after his cerebrovascular accident, using his left hand, right

hand, or both hands. Note the tendency to use more colours when using the left hand.

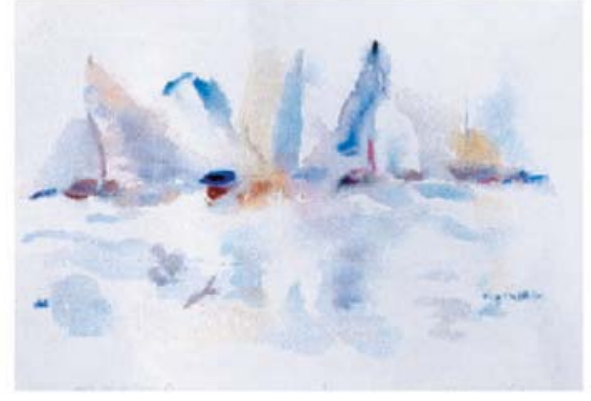

Both hands

structured organisation and bolder colours. On clinical evaluation, patient 2 also showed increased emotionality, which has been shown to influence creativity in other painters. ${ }^{40}$ These observations suggest that the artistic modifications in our patients might be due not only to mild executive dysfunction, but also to a moderate loss of emotional control.

In conclusion, we suggest that the new painting style adopted by these painters may be attributed to mild changes in executive functions, semantic capacities, and emotional regulation. While the change in their artistic behaviour seemed to exceed the sum of the emotional and cognitive manifestations related to their stroke, our data strongly suggest that these modifications can, at least partly, explain the change in style. The lack of strict formal rules in artistic creativity allows the development of new abilities after brain dysfunction, which depend not only on the artist's personality, but also on the lesion site and the ability of the brain to reorganise. ${ }^{41}$ The effect of focal brain lesions on individuals highly skilled in artistic expression provides a unique opportunity to study neuro-aesthetics, the neuroscience discipline dealing with the neurobiology of art, that is, the relationship between the brain and the artistic mind.

\section{ACKNOWLEDGEMENTS}

We would like to thank Valentina Palma and Jean Ott for their analysis of the painters' work, the patients for their paintings, and Tom Barkas for reading the manuscript.

\section{Authors' affiliations}

J M Annoni, G Devuyst, A Carota, L Bruggimann, J Bogousslavsky, Department of Neurology, Lausanne University Hospital, 1011 Lausanne, Switzerland

A Carota, Centro ricerche in neuropsicologia I.R.C.C.S, Fondatione Santa Lucia, Via Ardeatina 307, 00172 Rome, Italy

This work was supported by the Swiss National Science Foundation Igrant nos. 3151AO-102271 to JM Annoni and 3200-061342.00 to J Bogousslavsky) and by the Biaggi Foundation

Competing interests: none declared

\section{APPENDIX A}

\section{TO STYLISE}

to synthesise the essential elements of the shape and colours of that which is to be represented by simplifying them and subordinating the realisation of this portrayal to a particular aesthetic purpose. The concept is thus suggested by small elements (features, spots of colour, etc), rather than explicitly detailed.

\section{SYMBOLIC}

in figurative art, the process of transmitting specific concepts by means of the representation of images and elements suggestive of these concepts, but which have a figurative autonomy regarding the concrete reality.

\section{ABSTRACT ART}

artistic tendency that discards the representation of the external world, the aim of which is the formal message and visual perception itself. The pictorial language that ensues from this tendency expresses itself through the simplification and decomposition of shapes.

\section{FIGURATIVE ART}

the representation of truth by figures. Artistic language that resorts to the use of images and subjects which are present in the real world and universally known.

\section{GREATER ORGANISATION OF THE STRUCTURE}

to produce a picture balanced in the construction of each element, so that the composition is harmonious and well proportioned in the final work.

\section{GEOMETRIC ORGANISATION}

to structure a portrayal in a linear, ordered, and rigorous way, as if the arrangement of each element had to be measured. 


\section{STRONG IMPORTANCE OF EVERY DETAIL}

to express every element of the composition in its shading, originality, and formal characteristics.

\section{EMOTIONAL FORCE}

artistic language which is able to provoke strong emotional feelings due to a particular use of colours, shapes, design, etc.

\section{APPENDIX B}

Comments on the paintings of patients 1 and 2 paintings before and after stroke by an art critic (AC) and a professional artist (PA). The patients lent us ten (patient 1) or six (patient 2) paintings of different sizes. Half of these paintings were from the 4 years before the stroke and half from the year following the stroke. A standard A4 reproduction of the paintings was sent to the judges, to avoid size effects. The judges were told which paintings were executed before, and which after, the stroke. AC is an art critic in Rome and PA a professional painter and sculptor in Lausanne. They did not know the patients and were not aware of the type of stroke or the subsequent deficits. They had no neurological knowledge and were only told that the patients had started to paint again after a stroke. Their analysis included global observation and general architecture, represented theme, style and characteristic of drawing, importance of details, colours, and aesthetic evaluation.

\section{Patient 1, top pictures fig 1}

Before stroke (fig 1A)

The picture shows a figurative representation. In the centre, there are two people, in vivid colours, who seem to float in a landscape, represented only by floral elements. The pictorial language is naive, evoking a primitive expression. However, there is an interesting difference in style in the representation of the trees; it seems that more thought has been given to these before starting painting. (AC)

The painting represents an idyllic Eden. Images taken from a conventional, but joyous, set. Light (divine) is nearly out of field. Space is organised around the horizon. (PA)

\section{After stroke (fig 1B)}

Simplification of the previous paintings. There is now an almost pure monochromic choice. On this blue, there are some light sources confined to the right half of the painting (sun, moon?) and around the single figures. These figures are now completely stylised (like slowly moving silhouettes) and move in an unreferenced space. There are some randomly situated geometric patterns, suggesting an elementary graphic language. (AC)

Very simplified painting: the elements are now abstract and the symbolic is present everywhere. Peripheral features are also abstract and suggestive of contradictory forces. The light/form relationship develops on its own. (PA)

\section{Patient 1, bottom pictures fig 1}

\section{Before stroke (fig l A)}

In this painting appears a determination to abandon figurative style in favour of colour, light, and abstraction. The allusion to Matisse is obvious. The painter shows a number of individuals completely independent of each other. Each object is represented as a silhouette illuminated by an internal light. (AC)

The painting represents an organised space, in which light is the principal subject. Imagery is more abstract, but the church, house, and cat are conventional representations. Naive art. (PA)
After stroke (fig 1B)

Similar stylisation of the same subject. The same representations are shown on a red background. The luminosity of the sun permits no colour work, except for some minor accentuation of pallor. (AC)

Simplified painting with abstract elements and symbolism. Strong signs of violence represented by "emissions" coming from one of the figures. Some allusions to Kandinsky. (PA)

\section{Patient 2, fig 4 \\ Before stroke}

This work alludes to the French impressionist school, particularly towards dissipation of form, as in Cezanne's work, which announces Cubism. The objects lose their classical definition because of the use of patches of pure colours, which tend to mix with one another. (AC)

Dissolving and superimposing figures, rejecting individual autonomy in aid of the whole. Oblique elements suggest violence and confusion. Weak contrasts. Abstract expressionism pattern. (PA)

\section{After stroke}

This work seems to search for shape consistency and to focus more on details represented in the first work. The red tonality allows a stronger relevance of each object, particularly due to the use of white. In the construction of the painting, it is possible to define lines structuring the spatial composition. This is almost a regression in its wish to clarify what was previously expressed only by colour. (AC)

More structured and geometric organisation, bolder colours, and contrasts. Each shape is more independent. Space organised around the horizon. Clear patterns suggest a free and confident painter. (PA)

\section{REFERENCES}

1 Zeki S. Essays on science and society. Artistic creativity and the brain. Science $2001 ; 293: 51-2$.

2 Jeziernicka B, Turowsk IK. [Drawings by patients with unilateral visuospatial agnosia.] Neurol Neurochir Pol 1978;12:595-601.

3 Mazzucchi A, Pesci G, Trento D. Cervello e pittura: effetti delle lesioni cerebrali sul linguaggio pittorico. Rome: Fratelli Palombi Editori, 1994.

4 Rumble $E$, Whurr R. An investigation into the drawing skills of aphasic adults. Int J Lang Commun Disord 1998;33:218-23.

5 Wapner W, Judd T, Gardner H. Visual agnosia in an artist. Cortex 1978; 14:343-64.

6 Vigouroux R, Bonnefoi B, Khalil R. [Pictorial creations of a painter presenting with left-sided neglect.] Rev Neurol (Paris) 1990;146:665-70.

7 Smith W, Mindelzun R, Miller B. Simultanagnosia through the eyes of an artist. Neurology 2003;60:1832-4

8 Goldenberg G. Loss of visual imagery and loss of visual knowledge-a case study. Neuropsychologia 1992;30:1081-99.

9 Miller B Boone K, Cummings J, et al. Functional correlates of musical and visual ability in frontotemporal dementia. Br J Psychiatry 2000;176:458-63

10 Mell J, Howard S, Miller B. Art and the brain: the influence of frontotemporal dementia on an accomplished artist. Neurology 2003;60:1707-10.

11 Tanabe H, Nakagawa Y, Ikeda M, et al. Selective loss of semantic memory for words. In: Ishikawa K, McGauch J, Sakata H, eds. Brain processes and memory. Tokyo: Elsevier, 1996:141-52

12 Cummings J, Zarit J. Probable Alzheimer's disease in an artist. JAMA 1987;258:2731-4.

13 Espinel C. de Kooning's late colours and forms: dementia, creativity, and the healing power of art. Lancet 1996;347:1096-8.

14 Sahas D. Dementia with Lewy bodies and the neurobehavioral decline of Mervyn Peake. Arch Neurol 2003;60:889-92.

15 Miller B, Cummings J, Mishkin F, et al. Emergence of artistic talent in frontotemporal dementia. Neurology 1998;51:978-82.

16 Carson S, Peterson J, Higgins D. Decreased latent inhibition is associated with increased creative achievement in high-functioning individuals. J Pers Soc Psychol 2003;85(3):499-506.

17 Kapur N. Paradoxical functional facilitation in brain-behaviour research. A critical review. Brain 1996;119:1775-90.

18 Heilman K, Nadeau S, Beversdorf D. Creative innovation: possible brain mechanisms. Neurocase 2003;9:369-79.

19 Jamison K. Mood disorders and patterns of creativity in British writers and artists. Psychiatry 1989;52:125-34.

20 Carota A, Staub F, Bogousslavsky J. Emotions, behaviours and mood changes in stroke. Curr Opin Neurol 2002; 15:57-69.

21 Ghika-Schmid F, Bogousslavsky J. Affective disorders following stroke. Eur Neurol 1997; 38:75-81. 
22 Bogousslavsky J. [The lost love of Gui and Madeleine. Emotional syndrome and right temporal behavior of Guillaume Apollinaire.] Rev Neurol 2003; 159: 171-9

23 Horowitz M, Wilner N, Alvarez W. Impact of events scale: a measure of subjective stress. Psychosom Med 1979:41:209-18.

24 Burgess $P$, Alderman N, Evans J, et al. The ecological validity of tests of executive function. J Int Neuropsychol Soc 1998;4:547-58.

25 Wilson B, Alderman N, Burgess P. Behavioural assessment of the dysexecutive syndrome (BADS) manual. Bury St Edmonds, UK: Thames Valley Test Company, 1996.

26 Barrash J, Anderson S, Jones R, et al. lowa Scales of Personality Change. Presented at the 25th Annual Meeting of the International Neuropsychological Society, Orlando, 1997.

27 Prigatano G, Ogano M, Amakusa B. A cross-cultural study on impaired selfawareness in Japanese patients with brain dysfunction. Neuropsychiatr Neuropsychol Behav Neurol 1997; 10:135-43.

28 Mendez M. Dementia as a window to the neurology of art. Med Hypotheses 2004;63:1-7.

29 Molle M, Marshall L, Lutzenberger W, et al. Enhanced dynamic complexity in the human EEG during creative thinking. Neurosci Lett 1996;208:61-4.

30 Blanke O, Ortigue S, Landis T. Colour neglect in an artist. Lancet 2003;361:264.

31 Papagno C. Progressive impairment of constructional abilities: a visuospatial sketchpad deficit? Neuropsychologia 2002;40:1858-67.

32 Zysset S, Huber O, Ferst E, et al. The anterior frontomedian cortex and evaluative judgment: an fMRI study. Neuroimage 2002; 15:983-91.

33 Annoni J, Pegna A, Michel C, et al. Motor perseverative behavior depending on side and site of cerebral lesion. Eur Neurol 1998:40:84-90.

34 Annoni J, Pegna A. Random motor generation in a finger tapping task: influence of spatial contingency and of cortical and subcortical hemispheric brain lesions. J Neurol Neurosurg Psychiatry 1997;63:654-9.
35 Annoni J, Khateb A, Gramigna S, et al. Chronic cognitive impairment following laterothalamic infarcts: a study of 9 cases. Arch Neurol 2003;60: 1439-43.

36 Garavan H, Ross T, Li S, et al. A parametric manipulation of central executive functioning. Cereb Cortex 2000;10:585-92.

37 Horne J. Sleep loss and "divergent" thinking ability. Sleep 1988;1 1:528-36.

38 Annoni J, Ptak R, Caldara-Schnetzer A, et al. Decoupling of autonomic and cognitive emotional reactions after cerebellar stroke. Ann Neurol 2003;53:654-8.

39 Van Ameringen M, Mancini C, Oakman J. The relationship of behavioral inhibition and shyness to anxiety disorder. J Nerv Ment Dis 1998;186:425-31.

40 Rusalov V, Poltavtseva L. [Temperament as a prerequisite of creative capabilities.] Zh Vyssh Nerv Deiat Im I P Pavlova 1997;47:451-60.

41 Annoni J, Michel C, Landis T, et al. [Variability of right hemisphere activation during semantic word processing in aphasic patients: an electrophysiologic study in three patients.] Rev Neurol 2002;158:317-31.

42 Spreen O, Strauss E. A compendium of neuropsychological testing: administration, norms and commentary, 2nd ed. New York: Oxford University Press, 1998.

43 Bruyer R, Schweich M. A clinical test battery of face processing. Int J Neurosci 1991;61:19-30.

44 Assal G. Batterie des examens neuropsychologiques du CHUV. Lausanne: Division autonome de Neuropsychologie, 1985.

45 Lépine J, Godchau M, Brun P, et al. Evaluation de l'anxiété et de la dépression chez des patients hospitalisés dans un service de médecine interne. Annales Médico-psychologiques 1985;143:175-89.

46 Hansenne M, Charles $G$, Pholien P, et al. Mesure subjective de l'impact d'un événement: traduction francaise et validation de l'échelle d'Horowitz. Psychologie Médicale 1993;25:86-8. 